\title{
ASSESSMENT OF GRANULATED MANURE FERTILIZER CENTRIFUGAL SPREADING FIELD SIMULATION
}

Vaidas Bivainis $^{1,2}$, Egle Jotautiene ${ }^{1}$, Raimonda Zinkeviciene ${ }^{1}$

${ }^{1}$ Vytautas Magnus University, Lithuania; ${ }^{2}$ Kaunas University of Technology, Lithuania

vaidas.bivainis@ktu.lt, egle.jotautiene@vdu.lt, zinkevicieneraimonda@gmail.com

\begin{abstract}
Lately, the use of organic granular fertilizers from manure with a lower environmental impact for fertilizing agricultural soils has received a lot of attention. The use of these granular organic fertilizers is relevant for the reason that this way of fertilization helps solve the problems caused by the quantities of manure generated in the livestock sector and also contributes to the overall environmental sustainability. Besides, to extend the experimental studies of the field research, when spreading of 4 and $6 \mathrm{~mm}$ diameter granular manure fertilizers was carried out with a two-disc centrifugal fertilizer spreader, it is important to proceed with the modelling studies of spreading of these organic fertilizers. Spreading of fertilizer modelling was developed by using the SOLIDWORKS computer program. This program was used to create a fertilizer hopper part with a discharge opening, several types of cone-shaped spreading discs and several types and different sizes of fertilizer spreading vanes. The required parameters of the test fertilizer particles were determined in previous experimental studies and taken into account to perform the fertilizer spreading modelling. A relatively close coincidence of the modelling results of the organic fertilizer granule spreading trajectory, fertilizer spreading field and spreading volume distribution was obtained with the results of experimental studies. The results of this research make it possible to expand the scope of the performed experimental studies and to determine the spreading parameters for even and controlled spreading of granular fertilizers. The main directions of modelling research are the effect of the cone angle of the spreading disc, the tilt angle of the spreading vanes and the effect of the position of the fertilizer hopper spout concerning the spreading discs on the spreading uniformity of granular fertilizers.
\end{abstract}

Keywords: granular fertilizer, centrifugal spreader, DEM, spreading performance, field simulation.

\section{Introduction}

Nowadays, the soils are negatively influenced by intensive agriculture and chemical farming. The use of granular manure fertilizers not only saves mineral fertilizers and manure is processed into secondary products, but also contributes to saving of the environment and soil. However, organic granular fertilizer spreading sets a goal to properly choose the most rational spreading parameters and fertilizer rates. Performing of such experiments is very expensive. In order to increase the efficiency of fertilizer use, various theoretical models and computer programs are used to study the dynamics of fertilizer application [1]. These methods ensure faster researches and save money.

In most cases, the theoretical models have been developed to determine the motion of one particle of granular fertilizer particles in the air. The obtained test results are important for the theoretical investigation of the interaction between the organic fertilizer granule and the fertilizer spreading centrifugal disk. This is enough to make engineering decisions to ensure the optimization of the technological process. However, the movement of different types of fertilizer particles or their flow at any time can be rapidly simulated by using computer simulations. Abbou-ou-cherif et al. [2] used the discrete element method (DEM) to describe spreading fertilizers on the soil. This method is considered an effective modelling tool [2-4].

Yinyan et al. simulated spreading performance and distribution pattern of a centrifugal variablerate fertilizer applicator on DEM [3]. The kinetics of fertilizer particle removal from a screw applicator, seed flows in various types of the hopper and other parameters were performed with DEM simulation by the researchers [5]. Ding et al. investigated the influence of fertilizer dual-banding with adjustable rates used DEM [6]. However, the spreading performance of organic granular fertilizers, especially having the cylindrical form, lacks modelling in scientific studies. It is known that the aerodynamic and physical properties of manure granular fertilizers significantly differ from granular mineral fertilizers [1].

Centrifugal fertilizer spreaders are currently widely used for spreading granular organic fertilizers [7]. Centrifugal fertilizer spreaders are used due to the advantages, such as high performance, high capacity, reliability, manoeuvrability, and simplicity of construction [8]. Accordingly, in this work spreading of manure granulated fertilizers on the soil with a double-centrifugal fertilizer spreader was chosen to be studied using EDEM software. 


\section{Materials and methods}

The spreading model of granular organic fertilizers by a centrifugal spreader was performed with the discrete element method (DEM) by using 4 and $6 \mathrm{~mm}$ diameter pallets. The characteristics of the pallets used for simulation are given in Table 1 below.

Table 1

Main characteristics of manure pellets for spreading discrete element modelling

\begin{tabular}{|c|c|c|}
\hline Characteristics & $\begin{array}{c}4 \mathrm{~mm} \text { diameter } \\
\text { pellets }\end{array}$ & $\begin{array}{c}6 \mathrm{~mm} \text { diameter } \\
\text { pellets }\end{array}$ \\
\hline Diameter, $\mathrm{mm}$ & $4.75 \pm 0.12^{*}$ & $5.28 \pm 0.80$ \\
\hline Length average, $\mathrm{mm}$ & $7.88 \pm 0.59$ & $10.38 \pm 0.73$ \\
\hline Length standard deviation, $\mathrm{mm}$ & 2.98 & 3.68 \\
\hline Volume average, $\mathrm{mm}^{3}$ & 139.55 & 227.28 \\
\hline Volume standard deviation, $\mathrm{mm}^{3}$ & 52.82 & 80.71 \\
\hline Length and volume distribution type & \multicolumn{2}{|c|}{ Normal } \\
\hline Bulk Density, $\mathrm{kg} \cdot \mathrm{m}^{-3}$ & $650.0 \pm 27.0$ & $700.0 \pm 15.0$ \\
\hline Solid Density, $\mathrm{kg} \cdot \mathrm{m}^{-3}$ & $1370.0 \pm 18.0$ & $1390.0 \pm 21.0$ \\
\hline Poisson's Ratio & \multicolumn{2}{|c|}{0.25} \\
\hline Young's Modulus, MPa & \multicolumn{2}{|c|}{75} \\
\hline Particle-particle Coefficient of Restitution & \multicolumn{2}{|c|}{0.61} \\
\hline Particle-particle Coefficient of Static Friction & \multicolumn{2}{|c|}{0.49} \\
\hline Particle-particle Coefficient of Kinetic Friction & \multicolumn{2}{|c|}{0.25} \\
\hline Particle-wall Coefficient of Restitution & \multicolumn{2}{|c|}{0.47} \\
\hline Particle-wall Coefficient of Static Friction & \multicolumn{2}{|c|}{$0.18 \pm 0.02$} \\
\hline Particle-wall Coefficient of Kinetic Friction & \multicolumn{2}{|c|}{$0.10 \pm 0.02$} \\
\hline
\end{tabular}

*Confidence interval at significance level $\alpha=0.05$

Some of these pallet characteristics (see columns 1-8 and 15-16 in Table 1) were experimentally determined [9] by the authors themselves in the previous studies. Other portion of the granule characteristic values required for modelling (e.g., Poison's ratio, Young's modulus, the parameters of contact, etc.) were selected by analysis of other authors' literature sources $[6 ; 10]$ on similar topics.

A three-core type theoretical particle in the granulation scattering modelling, a three-core type theoretical particle model was chosen, which was with most closely characteristics of the geometric shape of the investigated fertilizer granule. The model was chosen, which most closely characterizes the geometric shape of the investigated fertilizer granule that was used to proceed with the granulation spreading model. In Fig. 1 the isometric view of this particle model, with a diameter of $4.75 \mathrm{~mm}$ and a length of $7.88 \mathrm{~mm}$, is shown. An analogous particle model was also used to describe a $6 \mathrm{~mm}$ diameter granule of the fertilizer.

The type of distribution of the test particles and the parameters of this distribution must be specified in the modelling of spreading of fertilizer granules. From the experimental results it was found that the distribution of the fertilizer granule length is visually close to the Normal distribution. Fig. 2 gives a frequency histogram together with the Normal distribution curve of the $4 \mathrm{~mm}$ diameter granule length distribution. Fertilizer granule distribution similarity to the Normal distribution is approved by the length mean, mode, median values that are very close to each other, also the granule length distribution kurtosis, skewness coefficient values were obtained close to zero. The standard deviation required for the modelling of the granule light deviation is given in Table 1.

In addition to the parameters of the spreading particle, the spreader model and the parameters of this model are important in the modelling. A real centrifugal fertilizer spreader model with a real 1:1 scale was created by using the SolidWorks software package. Part of the fertilizer hopper was modelled with an adjustable fertilizer spreading opening, fertilizer spreading discs and two lengths (290 and $410 \mathrm{~mm}$ ) of adjustable tilt angle spreading vanes.

Isometric view of a spreading disc with two blades is given in Fig. 3, while in Fig. 4 a spreading disc analogous to the developed model, view of spreading vanes and part of the hopper are shown. 


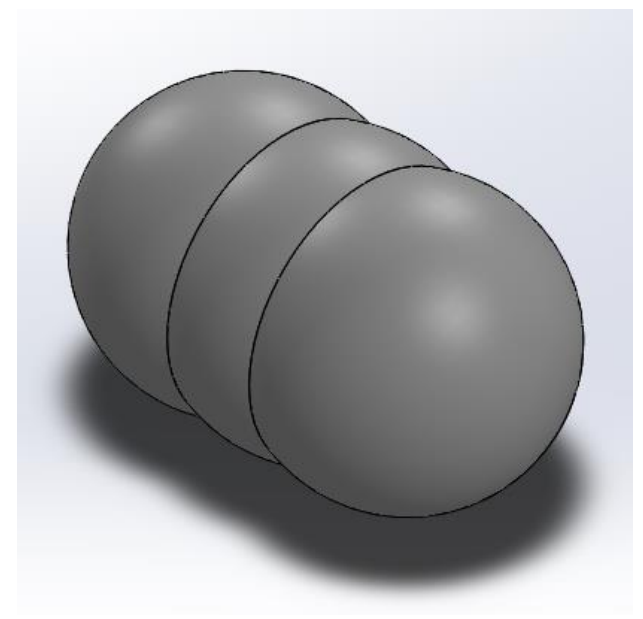

Fig. 1. Isometric view of $4 \mathbf{m m}$ diameter pellet simulation model

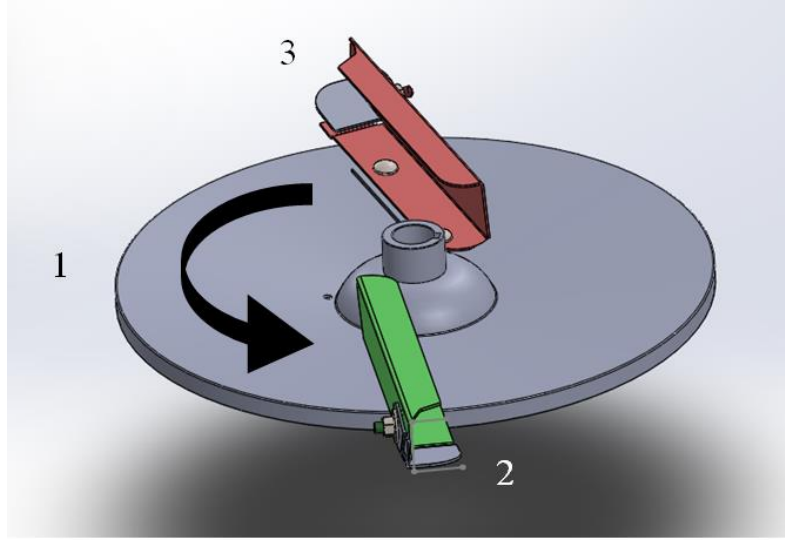

Fig. 3. Isometric view of fertilizer spreading disk with spreading blades model: 1 - disk rotation direction, $2-410 \mathrm{~mm}$ spreading vane and $3-290 \mathrm{~mm}$ spreading vane

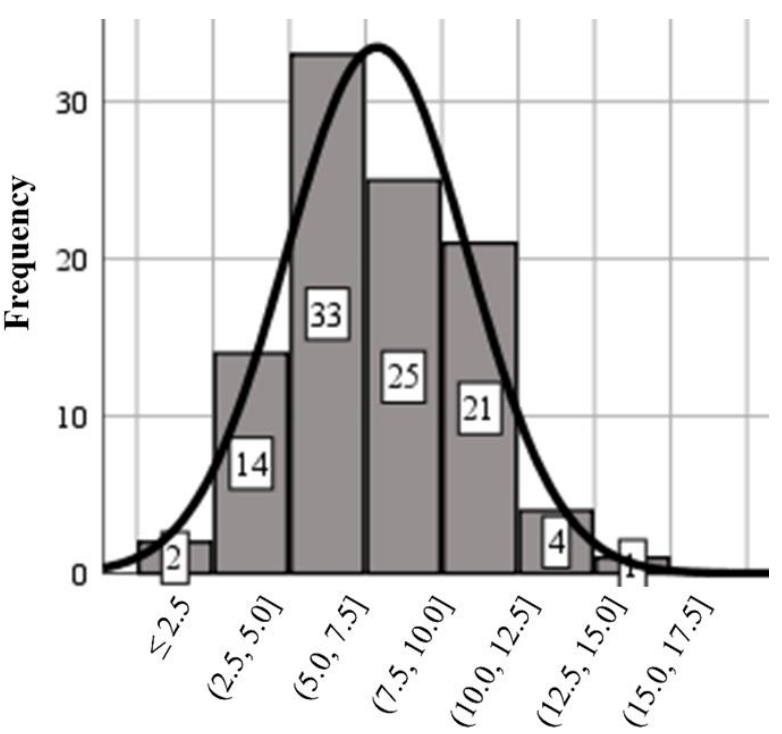

$4 \mathrm{~mm}$ diameter pellet lengt, $\mathrm{mm}$

Fig. 2. Histogram and Normal curve of distribution of $4 \mathbf{~ m m}$ diameter pellets length

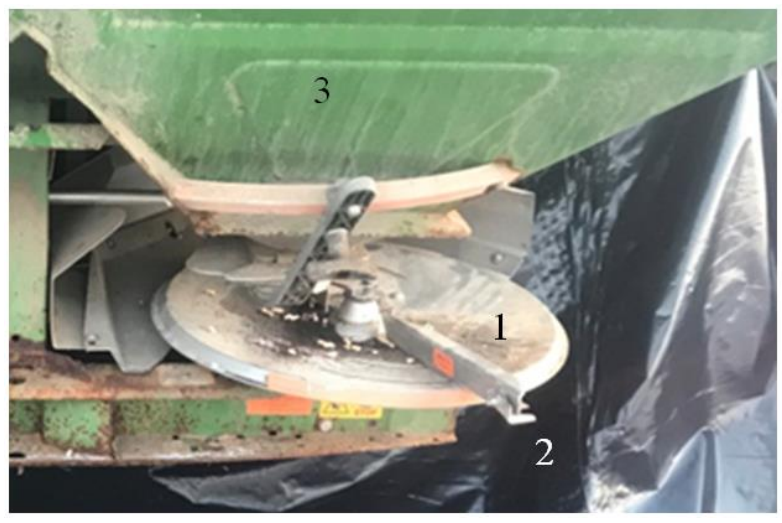

Fig. 4. General view of fertilizer spreader disk, blades and bunker: 1 - the disk, 2 - disk blade and 3 - bunker

The tilt angle of the blades was chosen according to the spreader manufacturer's recommendations to perform the spreading process modelling and in experimental studies. The rotation speed of the disk was about $870 \mathrm{rpm}$ [8], the working width of the fertilizer spread was approx. $14 \mathrm{~m}$, the distance of the discs from the ground was about $0.8 \mathrm{~m}$. The fertilizer application rate was about $200 \mathrm{~kg} \cdot \mathrm{ha}^{-1}$, the speed of the tractor with the spreader attached was $10 \mathrm{~km} \cdot \mathrm{h}^{-1}$; the target supply of pellets from the hopper opening was $0.1 \mathrm{~kg} \cdot \mathrm{s}^{-1}$. The effect of the wind was not evaluated in modelling studies.

\section{Results and discussion}

The modelling of spreading of granular fertilizers by the discrete element method lasted $2 \mathrm{~s}$, in total about $0.18 \mathrm{~kg}$ of granules were spread during that time. The displacement of the spreader was about $5.6 \mathrm{~m}$. The initial speed of the pellets moving through the bunker opening was $5 \mathrm{~m} \cdot \mathrm{s}^{-1}$. The speed of specific particles in different colours with a view of the arrangement of $4 \mathrm{~mm}$ diameter granules on the disk and the disk blades are shown in Fig. 5 below. The hopper and other fertilizer spreaders simulated during the creation of the computer model are not shown here to ensure the clarity of the image. In the following work, the scattering results of the performed $6 \mathrm{~mm}$ granules are not presented due to the identity of the obtained modelling results. 
A view of the granules and the spreading of the granules on a disc with paddles are shown in this picture. Visually this simulation image was partly consistent with the image of fertilizer spreading and spreading seen during the field experiment. The view of the part of the fertilizer spreader shown in Fig. 4 does not correspond partially to the view obtained during the modelling, because Fig. 4 was pictured at the moment when the spreader was standing with non-rotating discs.

For a more accurate verification of the modelling results, it would be appropriate to use a highspeed video to record how the particle flow rate is moving, how they are distributed on the disk, and how they are spread. The number of granules was set during the field studies and was calculated using boxes $400 \mathrm{~mm}$ wide and $500 \mathrm{~mm}$ long, placed every $1 \mathrm{~m}$ over the entire $14 \mathrm{~m}$ spreading width [7]. Boxsensors of the same size and placed according to the same layout were used for recording the mass of granules during the simulation. The general view of the layout of these boxes is given in Fig. 6. Only three boxes are given here for the sake of clarity. The number above the box indicates the mass of granules accumulated during modelling.

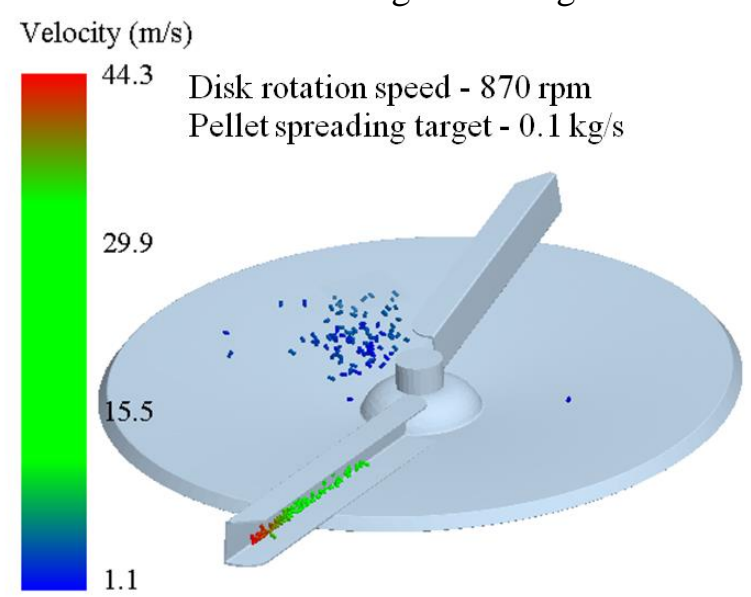

Fig. 5. View of $4 \mathrm{~mm}$ pellet velocity magnitude $\left(\mathrm{m} \cdot \mathrm{s}^{-1}\right)$ and pellet allocation on spreading disk and vanes

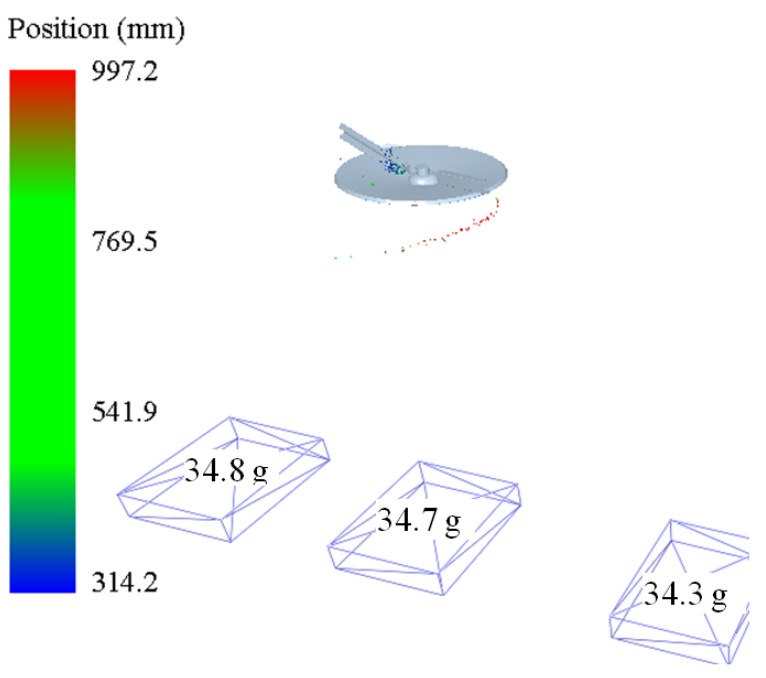

Fig. 6. View of granulated pellet spreading mass recording boxes displacement

Results of fertilizer spreading modelling are shown together with the results of analogous experimental studies [7] in Fig. 7. From the presented dependencies we can see that the trend of the modelling results obtained during the study is close enough to the experimental one.

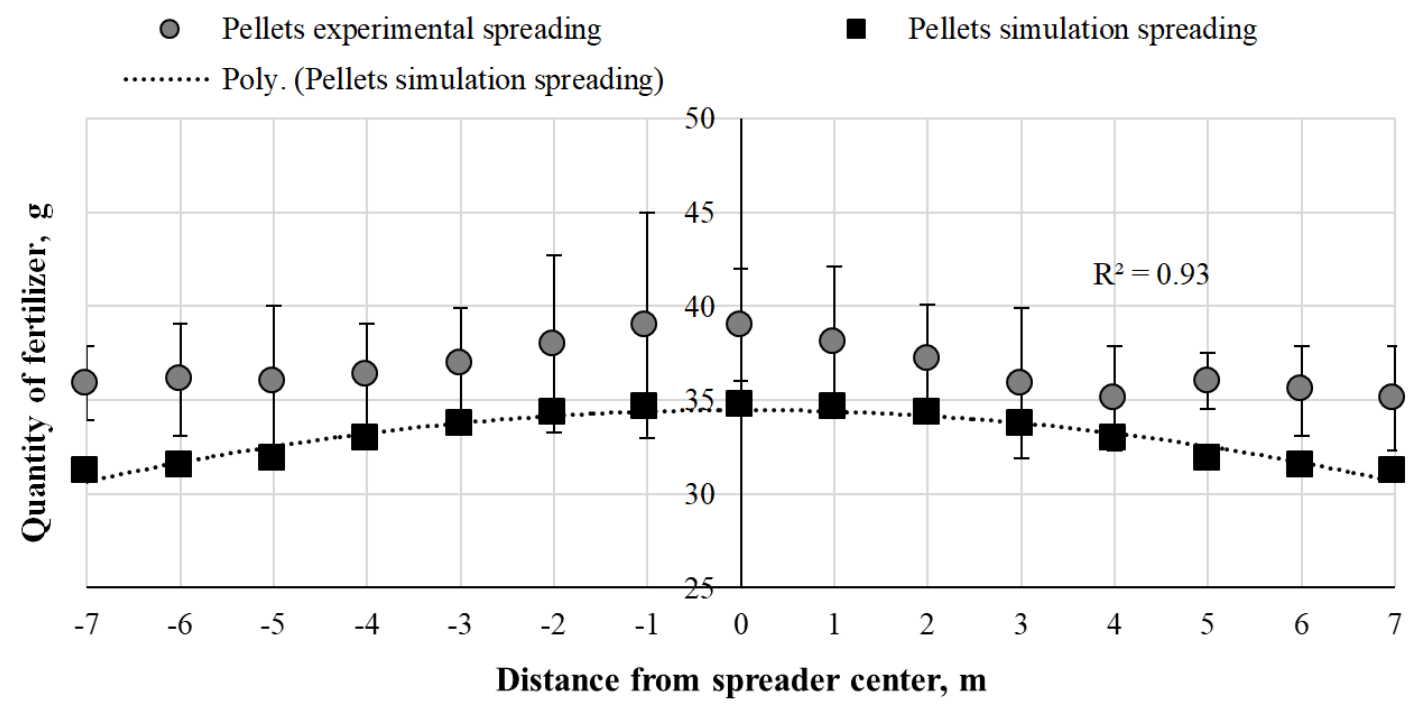

Fig. 7. Distribution of granulated manure pellet mass through all spread during experiments and spreading modelling 
The distribution of the fertilizer mass from the spreading centre set during the simulation is symmetrical, and the average of the numerical values was about $10 \%$ lower than the experimental one. This small discrepancy may have been caused by the properties of the granules, which were not precisely selected during the modelling (those that were not determined during the experiments, but were selected from analogous research sources) and other factors that possibly may not have been evaluated. The presented dependence of the modelling results was close to the quadratic polynomial; the coefficient of determination was 0.93 .

Good agreement between the presented modelling and experimental results allows assuming that the spreading of organic granular fertilizers can be modelled quite accurately using the discrete element method. Digital modelling provides possibilities to change the spreading and spreader parameters, to easily modify the spreader design and to estimate the effect of the changed parameters on the spreading results with sufficient accuracy.

\section{Conclusions}

1. During the granular manure fertilizer modelling studies with discrete elements it was obtained that the lack of specific properties of spreading granules, such as elastic modulus, angle of response, coefficient of restitution, etc. can and should be determined in experimental studies.

2. Results of the modelling of the discrete element method established that spreading of $4 \mathrm{~mm}$ diameter granular fertilizers was quite close to the results of experimental studies; it was found that the average of the numerical modelling results was about $10 \%$ lower than that obtained in the experimental studies.

3. The given results of fertilizer modelling and experimental research data showed that it is expedient to use DEM software for simulation of spreading performance.

\section{References}

[1] Koko J., Virin T. Optimization of a Fertilizer Spreading Process. Mathematics and Computers in Simulation, vol. 79, no 10, 2009, pp. 3099-3109.

[2] Abbou-ou-cherif E. M., Piron E., Chateauneuf A., Miclet D., Lenain R. and Koko J. On-the-field Simulation of Fertilizer Spreading: Part 1 - Modeling. Computers and Electronics in Agriculture, vol. 142, 2017, pp. 235-247.

[3] Yinyan S., Man C., Xiaochan W., Odhiambo M. O. and Weimin D. Numerical Simulation of Spreading Performance and Distribution Pattern of Centrifugal Variable-rate Fertilizer Applicator Based on DEM Software. Computers and Electronics in Agriculture, vol. 144, 2018, pp. 249-259.

[4] Yang L., et al. Fertilizer Sowing Simulation of a Variable-rate Fertilizer Applicator Based on EDEM. IFAC-PapersOnLine, vol. 51, no. 17, 2018, pp. 418-423.

[5] Przywara A. The Impact of Structural and Operational Parameters of the Centrifugal Disc Spreader on the Spatial Distribution of Fertilizer. Agriculture and Agricultural Science Procedia, vol. 7, 2015, pp. 215-222.

[6] Ding S., et al. Discrete Element Modelling (DEM) of Fertilizer Dual-banding With Adjustable Rates. Computers and Electronics in Agriculture, vol. 152, 2018, pp. 32-39.

[7] Jotautienè E., Bivainis V., Zinkevičienè R., Mieldažys R. An Investigation into the Spreading Uniformity of Granular Manure. Proceedings of International Conference "Engineering for Rural Development". May 20-22, 2020, Jelgava, Latvia, pp. 1648-1652.

[8] Spreading chart - AMAZONE Info-Portal. [online] [10.03.2021]. Available at: https://info.amazone.de/DisplayInfo.aspx $?$ id $=24656$.

[9] Jotautienè E., Bivainis V., Zinkevičienè R. and Aboltins A. An Assessment of Organic Granulated Manure Fertilizers Frictional Properties. Proceedings of International Conference "Engineering for Rural Development”. May 23-25, 2018, Jelgava, Latvia, pp. 1539-1544.

[10] Gallego E., Fuentes J. M., Ruiz Á., Hernández-Rodrigo G., Aguado P. and Ayuga F. Determination of Mechanical Properties for Wood Pellets Used in DEM Simulations. International Agrophysics, vol. 34 , no. 4 , 2020, pp. 485-494. 